Lisa Mundy ORCID iD: 0000-0002-7983-5232

\title{
Social Networking and Symptoms of Depression and Anxiety in Early Adolescence
}

Running title: Social networking and adolescent mental health symptoms

Lisa K. Mundy 1,2, Louise Canterford 1, Margarita Moreno-Betancur 2,3, Monsurul

Hoq ${ }^{1,3}$, Susan M Sawyer 1,2, Nicholas B. Allen ${ }^{4}$, and George C. Patton 1,2

${ }^{1}$ Centre for Adolescent Health, Murdoch Children's Research Institute, 50

Flemington Road, Parkville, Victoria, 3052, Australia

2Department of Paediatrics, University of Melbourne, Parkville, Victoria, 3052,

Australia

${ }^{3}$ Clinical Epidemiology and Biostatistics Unit, Murdoch Children's Research

Institute, 50 Flemington Road, Parkville, Victoria, 3052, Australia

4Department of Psychology, University of Oregon, Eugene OR 97403-1227, USA

Corresponding author: Dr. Lisa Kate Mundy

Murdoch Children's Research Institute, 50 Flemington Road, Parkville, Victoria, 3052, Australia Telephone: +61(0)39345 7978, Fax: +61(0)393456343

Email: lisa.mundy@mcri.edu.au

\section{Acknowledgements}

This research was supported by Australia's National Health and Medical Research Council (NHMRC; project grants \#1010018 and \#1122189), the Australian Rotary

This is the author manuscript accepted for publication and undergone full peer review but has not been through the copyediting, typesetting, pagination and proofreading process, which may lead to differences between this version and the Version of Record. Please cite this article as doi: 10.1002/da.23117.

This article is protected by copyright. All rights reserved. 
Health, the Victorian and Commonwealth Departments of Education and Training and the Royal Children's Hospital Foundation. Murdoch Children's Research Institute (MCRI) research is supported by the Victorian Government's Operational Infrastructure Program. Professor Patton is supported by a Senior Principal Research Fellowship from NHMRC. Study data were collected and managed using REDCap electronic data capture tools hosted at MCRI. REDCap (Research Electronic Data Capture) is a secure, web-based application designed to support data capture for research studies, providing: 1) an intuitive interface for validated data entry; 2) audit trails for tracking data manipulation and export procedures; 3) automated export procedures for seamless data downloads to common statistical packages; and 4) procedures for importing data from external sources (Harris et al., 2019; Harris et al., 2009). We thank the families and schools who participated in this study and staff and volunteers involved in data collection.

\section{Conflict of interests}

The authors declare that there are no conflict of interests.

\section{ABSTRACT}

Background: Use of social networking in later childhood and adolescence has risen quickly. The consequences of these changes for mental health are debated but require further empirical evaluation.

Methods: Using data from the Childhood to Adolescence Transition Study ( $\mathrm{n}=$ 1156), duration of social networking use was measured annually at four time points from 11.9 to 14.8 years of age ( $\geq 1$ hour/day indicating high use). Crosssectional and prospective relationships between social networking use and depressive and anxiety symptoms were examined.

Results: In adjusted (age, socioeconomic status, prior mental health history) cross-sectional analyses, females with high social networking use had greater This article is protected by copyright. All rights reserved. 
odds of depressive (OR 2.15, 95\% CI 1.58-2.91) and anxiety symptoms (OR 1.99, 95\% 1.32-3.00) than those that used a few minutes at most, while males with high social networking use had 1.60 greater odds of reporting depressive symptoms (95\% CI 1.09-2.35). For females an increased odds of depressive symptoms at age 14.8 was observed for high social networking use at one previous wave and at two or three previous waves, even after adjustment (OR 1.76, 95\% CI: 1.11-2.78; OR 2.06, 95\% CI 1.27-3.37, respectively) compared to no wave of high use.

Conclusions: Our results suggest weak to moderate increased odds of depression and anxiety in girls and boys with high social networking use versus low/normal use. These findings indicate that prevention programs for early mental health problems might benefit from targeting social networking use in early adolescence.

Key words: Anxiety/Anxiety Disorders, Depression, Child/Adolescent, Computer/Internet Technology, Epidemiology

\section{INTRODUCTION}

Fifty percent of mental health problems begin by 14 years of age with symptoms commonly emerging in late childhood (Kessler et al., 2005). In recent years, rates of mental health problems in youth appear to be increasing (Twenge, Cooper, Joiner, Duffy, \& Binau, 2019). Digital social networking has been implicated as a possible contributor but strong evidence for this assertion has been scant (Twenge et al., 2019).

Social networking sites are defined as internet-based applications that allow individuals to connect through the creation and exchange of user-based content (Seabrook, Kern, \& Rickard, 2016). Since the introduction of social networking, rates of use have risen sharply and it is now a major part of young people's lives. Current estimates suggest $97 \%$ of adolescents in the US are active

This article is protected by copyright. All rights reserved. 
on social networking sites (Anderson \& Jiang, 2018). There is much debate about the effects of increasing social networking by children (Bell, Bishop, \& Przybylski, 2015), with many studies showing significant associations but often with small effect sizes that suggest weak effects and the likelihood of significant moderating factors (Orben, Dienlin, \& Przybylski, 2019; Orben \& Przybylski, 2019).

Social networking shifts interactions with the external world in late childhood and adolescence, particularly with the peer group (O'Keeffe, ClarkePearson, \& Council on Comminications and Media, 2011). Its benefits include greater social connection and learning, as well as access to information and the development of skills in technology (O'Keeffe et al., 2011). However, there are also potential negative effects on mental health. Engagement with peers, central in identity development and establishment of self-regulation, may be altered with extensive social networking (O'Keeffe et al., 2011). Risks also arise through online hazards including cyberbullying, sexting, invasion of privacy and a heightened sensitivity to body image (O'Keeffe et al., 2011). Social networking may also affect mental health through disruption of sleep, physical activity and face-to-face peer interactions (O'Keeffe et al., 2011; Viner et al., 2019). In the latter scenarios, any link between social networking and mental health problems is likely to be more immediate and proximal, whereas the other mechanisms may explain a more distal relationship.

One limitation of earlier research examining the association between social networking and mental health has been a failure to control for the possibility that children and adolescents with mental health problems are more likely to use social networking sites (Ybarra, Alexander, \& Mitchell, 2005). Specifically, most previous studies fail to control for a prior history of mental health problems (McCrae, Gettings, \& Purssell, 2017). Although there have been

This article is protected by copyright. All rights reserved. 
some prospective studies that have extended beyond 12 months (e.g., Boers, Afzali, Newton, \& Conrod, 2019; Booker, Kelly, \& Sacker, 2018; Coyne, Rogers, Zurcher, Stockdale, \& Booth, 2020; McCrae et al., 2017), most have been crosssectional or with short-term follow up. Also, most studies have focused on older adolescents or young adults (Orben et al., 2019), which is often after the onset of mental health problems. Furthermore, many studies have focused on only one social networking platform but the majority of adolescents use multiple platforms (Hill et al., 2016).

This study addresses these limitations by examining the longitudinal relationships between levels of social networking use and symptoms of depression and anxiety in a large population-based sample of young adolescents including adjustment for prior history of mental health problems. These relationships will be examined separately for males and females given previous studies that have observed gender differences in associations between social networking and mental health (Booker et al., 2018). The first analyses examine cross-sectional (proximal) associations between longer duration of social networking use and high depressive and anxiety symptoms across four yearly assessments. The second examines whether high levels of social networking in early adolescence predict subsequent emergence of mental health problems.

\section{METHOD}

\section{Study Population and Design}

Data were from the Childhood to Adolescence Transition Study (CATS). The full design is reported elsewhere (Mundy et al., 2013). Briefly, students were invited from a stratified random sample of 43 primary schools (Government, Catholic, Independent) in Melbourne, Australia, in 2012. All grade three children

This article is protected by copyright. All rights reserved. 
(aged 8-9 years; fourth year of formal schooling) in the selected schools were invited to participate. Of the 2289 invited children, 1239 (54\%) were recruited.

\section{Procedure}

Participants were followed up annually from wave 1 (aged 8-9 years; 2012) to wave 7 (aged 14-15 years; 2018). Data collection occurred through student self-report questionnaires in schools until wave 4 and alternative arrangements were made for those unable to attend. In waves 5 and 6 , students at schools with 10 or more participants completed questionnaires at school. Other students completed questionnaires online, via post or by Computer Assisted Telephone Interview (CATI). In wave 7, all data collection was completed either online, via post or by CATI.

\section{Ethical Considerations}

Ethics approval was granted by the Royal Children's Hospital Human Research Ethics Committee (\#31089). Permission was granted from the Victorian Department of Education and Training and the Catholic Education Office Melbourne to recruit through their schools. Children were recruited through active, written, informed parent consent.

\section{Measures}

Depressive and anxiety symptoms. Depressive symptoms were measured using self-report on the Short Mood and Feelings Questionnaire (SMFQ) (Angold, Costello, Pickles, Winder, \& Silver, 1995). Items were scored on a 5-point Likert scale, ranging from 0 (never) to 4 (almost always). They were recoded to a 3-point scale (0 (not true); 1 (sometimes true); 2 (true)) to match the original SMFQ scoring. Two items ('I felt miserable and unhappy', 'I didn't enjoy anything at all') were included in waves 1 and 2 (to reduce participant burden) and the full 13 items were included in waves 3-7. The time frame was 'in the past two weeks'. The This article is protected by copyright. All rights reserved. 
total score was dichotomised to define presence of depressive symptoms using a cut-point of 2 or more for the two item scale (Rhew et al., 2010) and 6 or more for the full scale (Katon, Russo, Richardson, McCauley, \& Lozano, 2008).

Anxiety symptoms were assessed using the short Spence Children's Anxiety Scale (SCAS) (Reardon, Spence, Hesse, Shakir, \& Creswell, 2018; Spence, Barrett, \& Turner, 2003). Items were scored on a 5-point Likert scale, ranging from 0 (never) to 4 (almost always). They were recoded to a 4-point scale (0 (never) to 3 (always)) to match the original SCAS scoring. Two items ('I worry about things', 'I feel afraid') were included in waves 1 and 2 and the full 8 items were included in waves 3-7. The time frame was 'in the past two weeks'. The total score was dichotomised using a cut-point of 3 or more for the two-item scale (a child scoring $\geq 3$ answered at least 'often' on at least one of the two items) and 11 or more for the full short version (captures those who reported at least 'some' anxiety on all items) to define presence of anxiety symptoms.

Social networking use. Students reported their social networking use and duration of use in waves 4-7 (ages 11-12 through 14-15). They were asked: "Do you use any of the following social networking sites?" A list was provided with the option to specify others. Students who indicated that they used a social networking site were asked to report duration of use across all sites for a normal school day. The duration item was scored on a six-point scale from "none" to "4 or more hours" and then collapsed into three categories ("none or a few minutes", "30 minutes to 1 hours","1 hour +") based on the distribution of the data and in line with other studies (Selfhout, Branje, Delsing, ter Bogt, \& Meeus, 2009). Those that did not use any social networking sites were assigned to the "none or a few minutes" category. A high duration of social networking use was defined as using social networking sites for 1 hour + on school days (with results for 2 hours or more presented in the supplementary material). A measure of incident and This article is protected by copyright. All rights reserved. 
persistent high duration use was derived indicating high duration of use at a single wave or at two or three waves based on data from waves 4-6.

Covariates. To address potential confounding, age (in months; meancentred) and family socioeconomic status (SES) (both measured at wave 1) were adjusted for in analyses. SES was calculated from home postcode using the Index of Relative Socio-economic Advantage and Disadvantage (IRSAD) from the Australian Bureau of Statistics Socio-Economic Index for Areas (SEIFA IRSAD quintile).

A variable was generated to indicate if depressive symptoms were present in waves 1-3: (i) no waves ('not present'), (ii) at one wave only ('single episode'), or (iii) at two or three waves ('persistent'). Similarly, a three-level variable was generated to indicate the presence of anxiety symptoms during waves 1-3.

\section{Statistical Analysis}

Two analyses were conducted for each outcome to examine the crosssectional (short-term/proximal) and longitudinal (longer-term/distal) effects of social networking on mental health. All analyses were conducted separately for females and males.

The cross-sectional association between duration of social networking use and mental health symptoms at each wave was estimated using logistic generalised estimating equations (exchangeable correlation structure, robust standard errors) to account for repeated measures within individuals. Unadjusted models were initially fitted and then adjusted for age and SES. We further adjusted for mental health symptoms at the previous wave.

The effect of incident and persistent high duration of social networking use (waves 4-6) on mental health symptoms at wave 7 was estimated using logistic regression analysis. Unadjusted models were fitted and then adjusted for

This article is protected by copyright. All rights reserved. 
age and SES. Further adjustment was made for prior history of mental health symptoms (waves 1-3), in addition to all previously mentioned covariates.

Several analysis variables were subject to missing data. In the first analysis, an available case approach was used and in the second analysis, missing data were handled using multiple imputation with full details provided in the supplementary material.

\section{RESULTS}

\section{Description of sample}

Of the 1239 students recruited, 83 (6.7\%) were excluded because they had no social networking data, resulting in 1156 participants (623 females, 533 males). Average age at recruitment was 9.0 years (Figure 1). Table 1 summarises the duration of social networking use. Just over ten percent of females used social networking sites for more than one hour a day at wave 4, which increased to more than half at waves 6 and 7. Under ten percent of males used social networking sites for more than one hour a day at wave 5 , which increased to over $40 \%$ at wave 7. A summary of the duration of social networking use when high use is defined as 2 hours or more is presented in the supplementary material.

Prevalence of mental health symptoms increased over the 4 waves and mental health symptoms were more prevalent amongst females (Table 1).

\section{Cross-sectional relationships between duration of social networking and mental health}

In cross-sectional analyses, females who used social networking for more than one hour had just over two-fold greater odds of reporting mental health symptoms when compared with those who used social networking for a few minutes at most (Table 2). Results were similar when adjusting for age, SES and This article is protected by copyright. All rights reserved. 
prior mental health history (depressive symptoms: OR 2.15, 95\% CI 1.58-2.91; anxiety symptoms: OR 1.99, 95\% CI 1.32-3.00). However, associations were smaller when comparing those who used social networking for 30 minutes to 1 hour on a school day with those who used a few minutes.

Males who used social networking for more than one hour had 1.54 greater odds of reporting depressive symptoms (95\% CI 1.09-2.18) compared with those who used a few minutes (Table 2). Results were similar when adjusting for age, SES and prior mental health history (OR 1.60, 95\% CI 1.09-2.35). As with females, these associations were smaller when comparing males who used social networking for 30 minutes to 1 hour on a school day with males who used a few minutes. There was little evidence of an association between duration of social networking use and anxiety symptoms in males (Table 2). Results were consistent when categorising heavy social networking as 2 hours or more (refer to the supplementary material).

\section{Longitudinal relationships between duration of social networking and mental health}

In longitudinal analyses, for females, there was some evidence that reporting a high duration of social networking use (1+ hour) at only one previous wave (incident), was related to higher odds of reporting depressive symptoms in wave 7 (OR 1.79, 95\% CI 1.14-2.80; Table 3) compared with those that did not use social networking for $1+$ hour at any previous wave. The estimate was similar when adjusted for age, SES and prior history of mental health problems (OR 1.76, 95\% CI 1.11-2.78). There was little evidence of an effect of high duration of social networking use at only one previous wave on depression symptoms for males (OR $1.03,95 \%$ CI 0.55-1.91, after adjustment). For females, persistent high duration of social networking use (operationalised as high usage at two or three waves over

This article is protected by copyright. All rights reserved. 
waves 4-6), was related to an approximately 2-fold increase in the likelihood of reporting depressive symptoms in wave 7 (OR 2.23, 95\% CI 1.40-3.54; Table 3) compared with those who did not use social networking for $1+$ hour at previous waves. This estimate was similar after adjustment for age, SES and prior history of mental health symptoms (OR 2.06, 95\% CI 1.27-3.37). There was little evidence for an effect of high duration of social networking use at two or three previous waves on depression symptoms for males (OR 1.60, 95\% CI 0.77-3.35), after adjustment). When high social networking use was operationalised as 2 hours or more the direction of associations were comparable but with wider confidence intervals, especially for males (refer to Supplementary material).

Associations of a similar magnitude were observed between prior social networking use and subsequent anxiety symptoms, although evidence of an effect in females was weak (one wave only: OR 1.64, 95\% CI 0.91-2.93; two or three waves: OR: 1.58, 95\% CI: 0.87-2.88; after adjustment) and there was little evidence in males (one wave only: OR 1.97, 95\% CI 0.62-6.30; two or three waves: OR: 2.63, 95\% CI: 0.81-8.55; after adjustment; Table 4). Results of operationalising high social networking use as 2 hours or more are presented in the supplementary material. For females, the results were consistent and for males, there was some evidence that heavy social networking use was associated with greater odds of anxiety symptoms at wave 7 but with very wide confidence intervals.

\section{DISCUSSION}

This is one of the first large longitudinal population-based studies to examine social networking use and depressive and anxiety symptoms in early adolescence; an age when social networking use is escalating and mental health problems are emerging. Participants who reported using social networking sites

This article is protected by copyright. All rights reserved. 
for more than one hour a day on a school day were more likely to report symptoms of mental health problems, with effects being strongest for females and for depressive symptoms. Females engaging in high levels of social networking had an over two-fold greater odds for current depressive symptoms and anxiety symptoms, even when adjusting for prior mental health history. For males, over one hour of social networking per day was associated with 1.5 -fold greater odds for current depressive symptoms. When examining whether high levels of social networking use prospectively predicted future mental health symptoms, females with high levels of use at two or three prior waves had a two-fold greater odds of reporting depressive symptoms, even when adjusting for a prior history of depressive symptoms. There was a similar pattern for males but this effect was reduced when adjusting for prior mental health symptoms.

Existing research is mixed. Our results are consistent with other studies showing a link between social networking and mental health problems (Lin et al., 2016; Riehm et al., 2019), although other studies have reported no relationship (Coyne et al., 2020; Jensen, George, Russell, \& Odgers, 2019) and some have found users experience decreased depression (Bessière, Pressman, Kiesler, \& Kraut, 2010). Importantly, our study adjusted for prior mental health history, with findings in females similar to that by Riehm and colleagues (Riehm et al., 2019). However, for males using high levels of social networking at two or three waves, the effect was reduced, suggesting the possibility that males with high levels of depression are more likely to use social networking sites. Our study focuses on subclinical levels of symptoms and not clinically significant levels of depression and anxiety, which may explain divergence in results from some prior studies. We found little evidence of an association between social networking use and anxiety symptoms in males. Although there was some evidence of a short-term association for females, there was only weak evidence of a long-term association. This article is protected by copyright. All rights reserved. 
Few previous studies have examined anxiety as an outcome with most focusing on global wellbeing or mental health measures or only depression (Ivie, Pettitt, Moses, \& Allen, 2020). Of the few studies that have looked at both depression and anxiety, typically no association was found between social networking and either depression or anxiety (Coyne et al., 2020; Erevik et al., 2020).

Although we found associations between social network usage and mental health symptoms, the effect size of these associations were small to moderate (especially when adjusting for prior symptoms) and smaller than more wellestablished risk factors such as prior symptoms (Orben et al., 2019; Orben \& Przybylski, 2019). It is therefore unlikely that these effects can fully explain the recently observed cohort wide increases in youth mental health problems (Twenge et al., 2019).

Despite increases in social networking use and depressive symptoms that occur during early adolescence, earlier studies have focused on older adolescents and young adults (Lin et al., 2016). Young adolescents may be particularly susceptible to the risks associated with social networking given that their capacity for self-regulation and identity development are still forming, and their particular susceptibility to peers (O'Keeffe et al., 2011). Heavy users of social networking sites are more likely to experience envy when viewing others on these sites, an experience linked with depressive symptoms (Tandoc Jr, Ferrucci, \& Duffy, 2015). It is also possible that using social networking sites may expose young people to known risk factors for mental health problems, such as cyberbullying (O'Keeffe et al., 2011; Viner et al., 2019). Social networking may also displace other activities such as face-to-face interactions with peers, sleep or physical activity (Viner et al., 2019). Although not able to test specific mechanisms as part of this study, our

This article is protected by copyright. All rights reserved. 
results suggest that the effects of social networking on mental health may be both proximal and distal.

The large longitudinal population-based sample, with a narrow age range of young adolescents followed over time, and the ability to control for past mental health symptoms are study strengths. Separate measures of depressive and anxiety symptoms, rather than a global construct of psychological distress, is a further strength. The main limitation was the measure of social networking, which captured only duration and not content or the way it was used (Pea et al., 2012). There is evidence that active versus passive use of social networking sites may have different effects and that the number of friends on these sites may also affect symptoms (Hill et al., 2016). It is possible that females and males may use social networking sites differently, contributing to the gender differences observed (McCrae et al., 2017). Thus, further longitudinal research including measures of type as well as duration is required. Participants were also asked to recall their social networking activities for a normal school day, rather than using a time-use diary, direct tracking or other objective measures (Orben \& Przybylski, 2019). This may lead to potential recall bias given evidence that participants may not be accurate at estimating their media use (Scharkow, 2016). However, as heavy internet users have been shown to underestimate their time and infrequent users overreport, it may be less likely that misreporting would affect the results of this study (Scharkow, 2016).

Early adolescence is a time when young people are increasingly using social networking. In our study, just over $10 \%$ of females at 11.9 years of age were using social networking sites for more than an hour a day, a figure that had dramatically risen to over 1 in 2 females three years later. A similar pattern was observed for males, although overall rates were lower. Of particular interest,

This article is protected by copyright. All rights reserved. 
when this study started collecting information about social networking, the mean age of participants was 12 years, a year younger than the minimum age required by many social networking sites. Thus, this study has important implications for parents, teachers, clinicians and researchers and the results should be considered in the development of regulatory frameworks. Current guidelines from the American Academy of Paediatrics advise that for children over six years of age, consistent limits should be in place for the time and types of media used (Chassiakos, Radesky, Christakis, Moreno, \& Cross, 2016). This study suggests that using social networking for over an hour a day can impact subclinical levels of adolescent mental health problems and thus should be considered as a part of multifaceted programs aimed at the prevention of mental health problems that are escalating in early adolescence. In the years since 2012, social networking use has increased rapidly with most adolescents now utilising these programs (Anderson \& Jiang, 2018). This has brought profound changes across peer and family relationships (Nesi, Choukas-Bradley, \& Prinstein, 2018), meaning even low-level users or those who choose to opt out may be impacted (Haidt \& Allen, 2020; Rosenquist, Fowler, \& Christakis, 2011).

\section{Conclusion}

High levels of social networking are linked with depressive symptoms in early adolescence, both proximally and distally. For females these effects persist when adjusting for previous depressive symptoms. Current use of social networking is also associated with anxiety symptoms in females. However, these associations are small to moderate and smaller than known risk factors. Notwithstanding this, high rates of social networking use suggest it is an important component to consider in prevention programs for mental health

This article is protected by copyright. All rights reserved. 
problems. This study provides important new insights into the associations between these phenomena during this critical phase of development.

\section{REFERENCES}

Anderson, M., \& Jiang, J. (2018). Teens, social media \& technology 2018. Pew Research Center, 31, 2018.

Angold, A., Costello, E. J., Pickles, A., Winder, F., \& Silver, D. (1995).

Development of a short questionnaire for use in epidemiological studies of depression in children and adolescents. International Journal of Methods in Psychiatric Research, 5, 237-249.

Bell, V., Bishop, D. V., \& Przybylski, A. K. (2015). The debate over digital technology and young people. BMJ, 351, h3064.

Bessière, K., Pressman, S., Kiesler, S., \& Kraut, R. (2010). Effects of internet use on health and depression: a longitudinal study. Journal of Medical Internet Research, 12(1), e6.

Boers, E., Afzali, M. H., Newton, N., \& Conrod, P. (2019). Association of Screen Time and Depression in Adolescence. JAMA pediatrics. Booker, C. L., Kelly, Y. J., \& Sacker, A. (2018). Gender differences in the associations between age trends of social media interaction and well-being among 10-15 year olds in the UK. BMC Public Health, 18(1), 321.

Chassiakos, Y. L. R., Radesky, J., Christakis, D., Moreno, M. A., \& Cross, C. (2016). Children and adolescents and digital media. Pediatrics, e20162593.

This article is protected by copyright. All rights reserved. 
Coyne, S. M., Rogers, A. A., Zurcher, J. D., Stockdale, L., \& Booth, M. (2020). Does time spent using social media impact mental health?: An eight year longitudinal study. Computers in Human Behavior, 104, 106160.

Erevik, E. K., Pallesen, S., Vedaa, Ø., Andreassen, C. S., Dhir, A., \& Torsheim, T. (2020). General and Alcohol-Related Social Media Use and Mental Health: a Large-Sample Longitudinal Study. INTERNATIONAL JOURNAL OF MENTAL HEALTH AND ADDICTION.

Haidt, J., \& Allen, N. (2020). Scrutinizing the effects of digital technology on mental health: Nature Publishing Group.

Harris, P. A., Taylor, R., Minor, B. L., Elliott, V., Fernandez, M., O'Neal, L.,... Kirby, J. (2019). The REDCap consortium: Building an international community of software platform partners. Journal of Biomedical Informatics, 95, 103208.

Harris, P. A., Taylor, R., Thielke, R., Payne, J., Gonzalez, N., \& Conde, J. G. (2009). Research electronic data capture (REDCap)—a metadatadriven methodology and workflow process for providing translational research informatics support. Journal of Biomedical Informatics, 42(2), 377-381.

Hill, D., Ameenuddin, N., Chassiakos, Y. R., Cross, C., Radesky, J., Hutchinson, J.,... Swanson, W. S. (2016). Media Use in School-Aged Children and Adolescents. Pediatrics, 138(5). doi:10.1542/peds.2016-2592

Ivie, E. J., Pettitt, A., Moses, L. J., \& Allen, N. B. (2020). A meta-analysis of the association between adolescent social media use and depressive symptoms. Journal of Affective Disorders.

This article is protected by copyright. All rights reserved. 
Jensen, M., George, M. J., Russell, M. R., \& Odgers, C. L. (2019). Young adolescents' digital technology use and mental health symptoms: Little evidence of longitudinal or daily linkages. Clinical Psychological Science, 7(6), 1416-1433.

Katon, W., Russo, J., Richardson, L., McCauley, E., \& Lozano, P. (2008). Anxiety and depression screening for youth in a primary care population. Ambulatory Pediatrics, 8(3), 182-188.

Kessler, R. C., Berglund, P., Demler, O., Jin, R., Merikangas, K. R., \& Walters, E. E. (2005). Lifetime prevalence and age-of-onset distributions of DSM-IV disorders in the National Comorbidity Survey Replication. Archives of General Psychiatry, 62(6), 593-602.

Lin, L. Y., Sidani, J. E., Shensa, A., Radovic, A., Miller, E., Colditz, J. B.,... Primack, B. A. (2016). Association between social media use and depression among U.S. young adults. Depression and Anxiety, 33(4), $323-331$.

McCrae, N., Gettings, S., \& Purssell, E. (2017). Social media and depressive symptoms in childhood and adolescence: A systematic review. Adolescent Research Review, 2(4), 315-330.

Mundy, L. K., Simmons, J., Allen, N. B., Viner, R., Bayer, J. K., Olds, T. S.,... Patton, G. C. (2013). Study protocol: the Childhood to Adolescence Transition Study (CATS). BMC Pediatrics, 13, 160.

Nesi, J., Choukas-Bradley, S., \& Prinstein, M. J. (2018). Transformation of adolescent peer relations in the social media context: Part $1-\mathrm{A}$ theoretical framework and application to dyadic peer relationships. Clinical Child and Family Psychology Review, 21(3), 267-294.

This article is protected by copyright. All rights reserved. 
O'Keeffe, G. S., Clarke-Pearson, K., \& Council on Comminications and Media. (2011). The Impact of Social Media on Children, Adolescents, and Families. Pediatrics, 127(4), 800-804.

Orben, A., Dienlin, T., \& Przybylski, A. K. (2019). Social media’s enduring effect on adolescent life satisfaction. Proceedings of the National Academy of Sciences, 116(21), 10226-10228.

Orben, A., \& Przybylski, A. K. (2019). Screens, teens, and psychological wellbeing: evidence from three time-use-diary studies. Psychological Science, 30(5), 682-696.

Pea, R., Nass, C., Meheula, L., Rance, M., Kumar, A., Bamford, H.,... Yang, S. (2012). Media use, face-to-face communication, media multitasking, and social well-being among 8-to 12-year-old girls. Developmental psychology, 48(2), 327.

Reardon, T., Spence, S. H., Hesse, J., Shakir, A., \& Creswell, C. (2018). Identifying children with anxiety disorders using brief versions of the Spence Children's Anxiety Scale for children, parents, and teachers. Psychological assessment, 30(10), 1342.

Rhew, I. C., Simpson, K., Tracy, M., Lymp, J., McCauley, E., Tsuang, D., \& Vander Stoep, A. (2010). Criterion validity of the Short Mood and Feelings Questionnaire and one-and two-item depression screens in young adolescents. Child and Adolescent Psychiatry and Mental Health, 4(1), 1.

Riehm, K. E., Feder, K. A., Tormohlen, K. N., Crum, R. M., Young, A. S., Green, K. M.,... Mojtabai, R. (2019). Associations between time spent using 
social media and internalizing and externalizing problems among US youth. JAMA Psychiatry, 76(12), 1266-1273.

Rosenquist, J. N., Fowler, J. H., \& Christakis, N. A. (2011). Social network determinants of depression. Molecular psychiatry, 16(3), 273-281.

Scharkow, M. (2016). The accuracy of self-reported internet use-A validation study using client log data. Communication Methods and Measures, 10(1), 13-27.

Seabrook, E. M., Kern, M. L., \& Rickard, N. S. (2016). Social networking sites, depression, and anxiety: a systematic review. JMIR Mental Health, 3(4), e50.

Selfhout, M. H., Branje, S. J., Delsing, M., ter Bogt, T. F., \& Meeus, W. H. (2009). Different types of Internet use, depression, and social anxiety: The role of perceived friendship quality. Journal of adolescence, 32(4), 819-833.

Spence, S. H., Barrett, P. M., \& Turner, C. M. (2003). Psychometric properties of the Spence Children's Anxiety Scale with young adolescents. Journal of Anxiety Disorders, 17(6), 605-625.

Tandoc Jr, E. C., Ferrucci, P., \& Duffy, M. (2015). Facebook use, envy, and depression among college students: Is facebooking depressing? Computers in Human Behavior, 43, 1390146.

Twenge, J. M., Cooper, A. B., Joiner, T. E., Duffy, M. E., \& Binau, S. G. (2019). Age, period, and cohort trends in mood disorder indicators and suicide-related outcomes in a nationally representative dataset, 2005-2017. Journal of Abnormal Psychology.

This article is protected by copyright. All rights reserved. 
Viner, R. M., Aswathikutty-Gireesh, A., Stiglic, N., Hudson, L. D., Goddings, A.L., Ward, J. L., \& Nicholls, D. E. (2019). Roles of cyberbullying, sleep, and physical activity in mediating the effects of social media use on mental health and wellbeing among young people in England: a secondary analysis of longitudinal data. The Lancet Child \& Adolescent Health.

Ybarra, M. L., Alexander, C., \& Mitchell, K. J. (2005). Depressive symptomatology, youth Internet use, and online interactions: A national survey. Journal of Adolescent Health, 36(1), 9-18.

Data availability statement: The data that support the findings of this study are available on request from the corresponding author. The data are not publicly available due to privacy or ethical restrictions.

This article is protected by copyright. All rights reserved. 
Table 1: Proportion of students using social networking sites by duration and proportion of students with mental health problems (by wave and sex) (available case analysis)

\begin{tabular}{|c|c|c|c|c|c|c|c|c|}
\hline & \multicolumn{2}{|c|}{ Wave 4} & \multicolumn{2}{|c|}{ Wave 5} & \multicolumn{2}{|c|}{ Wave 6} & \multicolumn{2}{|c|}{ Wave 7} \\
\hline & $\mathbf{n}$ & $\%$ & $\mathbf{n}$ & $\%$ & $\mathbf{n}$ & $\%$ & $\mathbf{n}$ & $\%$ \\
\hline Female & & & & & & & & \\
\hline Duration of social networking & 559 & - & 522 & - & 521 & - & 472 & - \\
\hline None or a few minutes & 344 & 61.5 & 199 & 38.1 & 104 & 20.0 & 72 & 15.3 \\
\hline 30 minutes to 2 hours & 140 & 25.0 & 151 & 28.9 & 152 & 29.2 & 136 & 28.8 \\
\hline 2 hours + & 75 & 13.4 & 172 & 33.0 & 265 & 50.9 & 264 & 55.9 \\
\hline Depressive symptoms & 554 & - & 496 & - & 516 & - & 468 & - \\
\hline Present & 90 & 16.3 & 125 & 25.2 & 184 & 35.7 & 191 & 40.8 \\
\hline Anxiety symptoms & 554 & - & 522 & - & 522 & - & 471 & - \\
\hline Present & 67 & 12.1 & 54 & 10.3 & 82 & 15.7 & 95 & 20.2 \\
\hline
\end{tabular}

Male

Duration of social networking $499 \quad-456 \quad-\quad 470 \quad-\quad 408$ -

None or a few minutes

$\begin{array}{llllllll}331 & 66.3 & 253 & 55.5 & 127 & 27.0 & 90 & 22.1\end{array}$

30 minutes to 2 hours

$\begin{array}{llllllll}126 & 25.3 & 115 & 25.2 & 163 & 34.7 & 139 & 34.1\end{array}$

2 hours +

$\begin{array}{llllllll}42 & 8.4 & 88 & 19.3 & 180 & 38.3 & 179 & 43.9\end{array}$

This article is protected by copyright. All rights reserved. 
Depressive symptoms

Present

Anxiety symptoms

Present
494

48

9.7

$\begin{array}{ll}64 & 14.7\end{array}$

$80 \quad 17.4$

$87 \quad 21.4$

486

459

466

410

15

3.1

16

3.5

20

4.3

21

5.1

This article is protected by copyright. All rights reserved. 
Table 2: Relationship between duration of social networking use (on a normal school day) and depressive and anxiety symptoms (average cross-sectional association across waves 4 to 7; available case analysis)

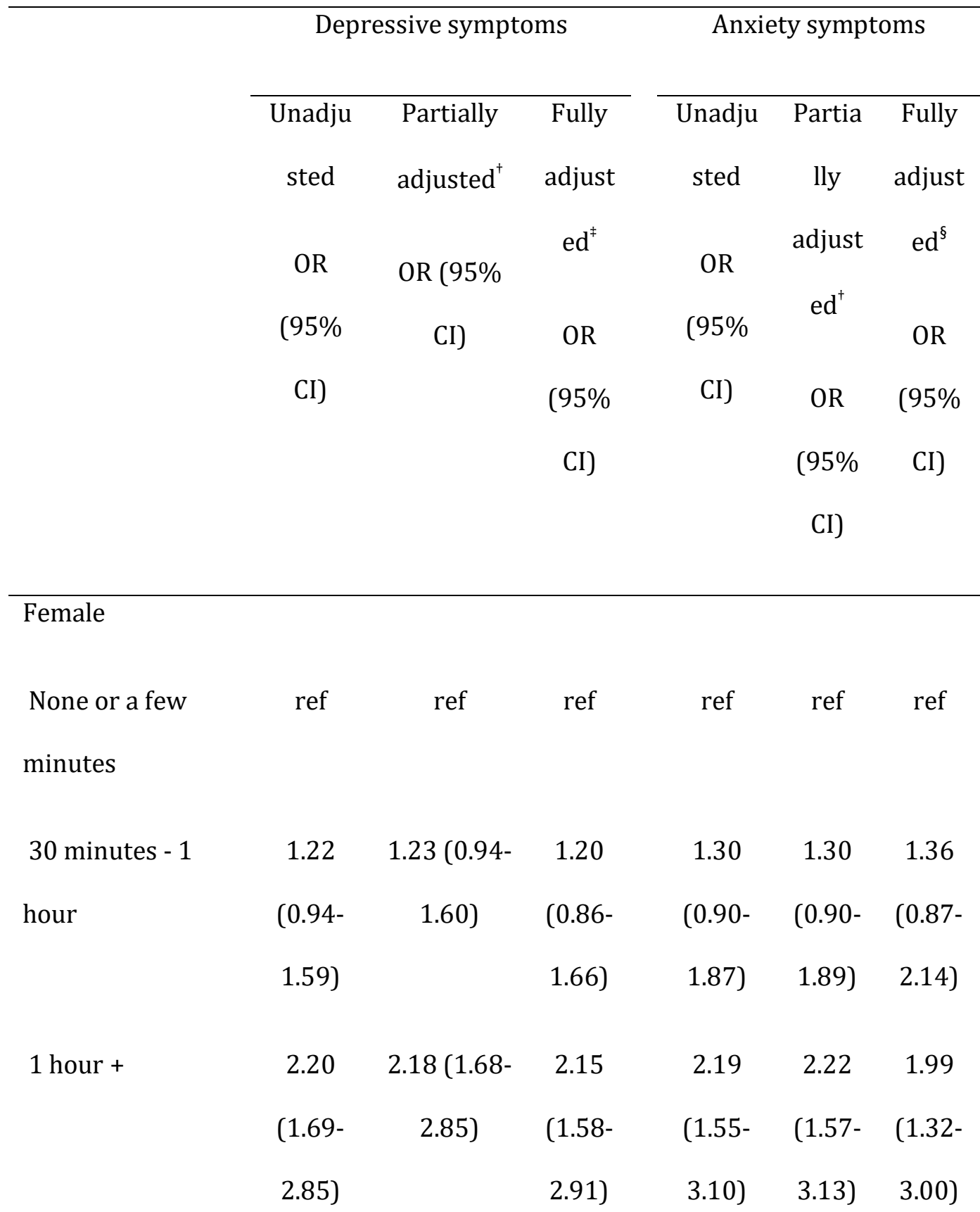

Male

None or a few

ref

ref

ref

ref ref ref

minutes

This article is protected by copyright. All rights reserved. 


$\begin{array}{lcccccc}30 \text { minutes - } 1 & 1.09 & 1.09(0.80- & 1.22 & 1.20 & 1.20 & 1.37 \\ \text { hour } & (0.80- & 1.48) & (0.86- & (0.69- & (0.69- & (0.75- \\ & 1.48) & & 1.72) & 2.08) & 2.10) & 2.50) \\ & & & & & & \\ 1 \text { hour }+ & 1.54 & 1.51(1.07- & 1.60 & 1.44 & 1.39 & 1.62 \\ & (1.09- & 2.13) & (1.09- & (0.76- & (0.73- & (0.78- \\ & & & 2.35) & 2.74) & 2.64) & 3.37)\end{array}$

\footnotetext{
${ }^{\dagger}$ Adjusted for SES (wave 1), age (wave 1)), and wave of data collection. ${ }^{\ddagger}$ Adjusted for SES (wave 1), age (wave 1)), wave of data collection, depressive symptoms at the prior wave, and anxiety symptoms at the prior wave. ${ }^{\S}$ Adjusted for SES (wave 1), age (wave 1)), wave of data collection, anxiety symptoms at the prior wave, and depressive symptoms at the prior wave.
}

This article is protected by copyright. All rights reserved. 
Table 3: Effect of high use of social networking across waves 4-6 on depressive symptoms in wave 7 (multiple imputation analysis)

\begin{tabular}{|c|c|c|c|c|c|}
\hline & $\mathrm{n}^{+}$ & $\begin{array}{l}\text { Depressive } \\
\text { symptoms }\end{array}$ & $\begin{array}{l}\text { Unadjusted } \\
\text { OR (95\% CI) }\end{array}$ & $\begin{array}{l}\text { Partially } \\
\text { adjusted }^{\S}\end{array}$ & $\begin{array}{c}\text { Fully } \\
\text { adjusted }^{\pi}\end{array}$ \\
\hline & & $\%(95 \% \mathrm{CI})^{\ddagger}$ & & $\begin{array}{l}\text { OR }(95 \% \\
\text { CI })\end{array}$ & OR $(95 \% \mathrm{CI})$ \\
\hline Female & & & & & \\
\hline Not present & 248 & $\begin{array}{c}31.8(25.6- \\
38.7)\end{array}$ & ref & ref & ref \\
\hline One wave & 178 & $\begin{array}{c}45.5(37.4- \\
53.8)\end{array}$ & $\begin{array}{c}1.79(1.14- \\
2.80)\end{array}$ & $\begin{array}{c}1.76 \\
(1.12- \\
2.77)\end{array}$ & $\begin{array}{c}1.76(1.11- \\
2.78)\end{array}$ \\
\hline $\begin{array}{l}\text { Two or three } \\
\text { waves }\end{array}$ & 197 & $\begin{array}{c}51.0(42.6- \\
59.3)\end{array}$ & $\begin{array}{c}2.23(1.40- \\
3.54)\end{array}$ & $\begin{array}{c}2.17 \\
(1.35- \\
3.49)\end{array}$ & $\begin{array}{c}2.06(1.27- \\
3.37)\end{array}$ \\
\hline Male & & & & & \\
\hline Not present & 286 & $\begin{array}{c}19.5(14.9- \\
25.0)\end{array}$ & ref & ref & ref \\
\hline One wave & 143 & $\begin{array}{c}21.3(14.3- \\
30.4)\end{array}$ & $\begin{array}{c}1.12(0.62- \\
1.99)\end{array}$ & $\begin{array}{c}1.09 \\
(0.60-\end{array}$ & $\begin{array}{c}1.03(0.55- \\
1.91)\end{array}$ \\
\hline Two or three & 103 & $31.0(20.4-$ & 1.85 (0.97- & $\begin{array}{c}1.96) \\
1.81 \\
(0.93-\end{array}$ & $1.60(0.77-$ \\
\hline
\end{tabular}

This article is protected by copyright. All rights reserved. 
${ }^{+}$Calculated using imputed percentage estimates and total number of students in the analysis sample $(\mathrm{N}=533$ males, $\mathrm{N}=623$ females $){ }^{\ddagger}$ Estimated marginal (population-average) unadjusted prevalence rate. ${ }^{\S}$ Adjusted for SES (wave 1) and age (wave 1))

${ }^{\pi}$ Adjusted for SES (wave 1), age (wave 1)), depressive symptoms (waves 1-3), and anxiety symptoms (waves 1-3).

This article is protected by copyright. All rights reserved. 
Table 4: Effect of high use of social networking across waves 4-6 on anxiety symptoms in wave 7 (multiple imputation analysis)

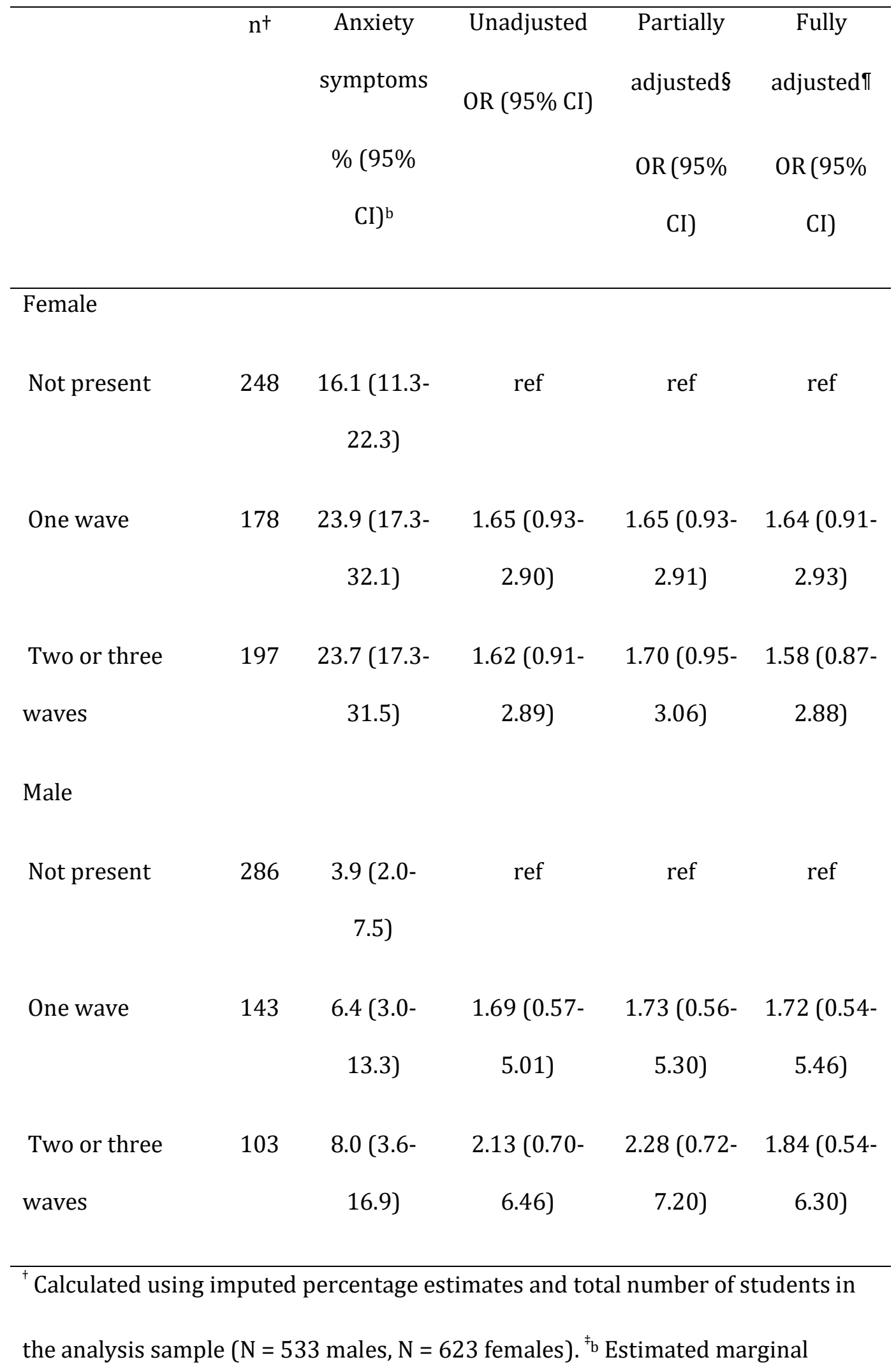

This article is protected by copyright. All rights reserved. 
(population-average) unadjusted prevalence rate. ${ }^{\S}$ Adjusted for SES (wave 1) and age (wave 1)) "Adjusted for SES (wave 1), age (wave 1)), anxiety symptoms (waves 1-3), and depressive symptoms (waves 1-3).

Figure 1: Mean age (standard deviation) of participants at each wave of CATS ( $\mathrm{n}=$ 623 females, $\mathrm{n}=533$ males)

\begin{tabular}{|c|c|c|c|c|c|c|c|}
\hline & Wave 1 & Wave 2 & Wave 3 & Wave 4 & Wave 5 & Wave 6 & Wave 7 \\
\hline Survey year & 2012 & 2013 & 2014 & 2015 & 2016 & 2017 & 2018 \\
\hline Age (Female) & $9.0(0.4)$ & $9.9(0.4)$ & $10.9(0.4)$ & $11.9(0.4)$ & $13.0(0.4)$ & $13.8(0.4)$ & $14.7(0.4)$ \\
\hline Age (Male) & $9.0(0.4)$ & $10.0(0.4)$ & $10.9(0.4)$ & $11.9(0.4)$ & $13.0(0.4)$ & $13.8(0.4)$ & $14.8(0.4)$ \\
\hline Response rates ${ }^{\mathrm{a}}$ & $1194(96)$ & $1156(93)$ & $1118(90)$ & $1067(86)$ & $993(80)$ & $997(80)$ & $899(73)$ \\
\hline
\end{tabular}

a Number of participants with valid survey responses and percentage out of the total recruited cohort $N=1239$

This article is protected by copyright. All rights reserved. 


\section{University Library}

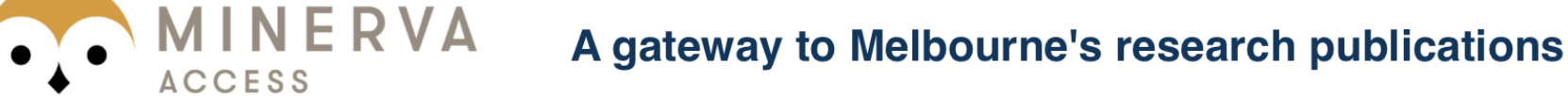

Minerva Access is the Institutional Repository of The University of Melbourne

Author/s:

Mundy, LK;Canterford, L;Moreno-Betancur, M;Hoq, M;Sawyer, SM;Allen, NB;Patton, GC

Title:

Social networking and symptoms of depression and anxiety in early adolescence

Date:

2020-11-22

Citation:

Mundy, L. K., Canterford, L., Moreno-Betancur, M., Hoq, M., Sawyer, S. M., Allen, N. B. \& Patton, G. C. (2020). Social networking and symptoms of depression and anxiety in early adolescence. DEPRESSION AND ANXIETY, 38 (5), pp.563-570. https://doi.org/10.1002/ da.23117.

Persistent Link:

http://hdl.handle.net/11343/276635 